\title{
Redefining Learning and Assessment Practices Impacting Aboriginal Students: Considering Aboriginal Priorities via Aboriginal and Western Worldviews
}

\author{
Tim R. Claypool and Jane P. Preston \\ University of Saskatchewan
}

\section{Author Note}

In preparation of this article, the authors gratefully acknowledge the support and assistance received from the Aboriginal Education Research Center (Marie Battiste and Yvonne Vizina), and members of the Partnership Initiative responsible for designing this project (representatives from the Saskatoon Tribal Council, Central Urban Métis Federation Inc. Local \#165, and the Greater Saskatoon Catholic School Division). The authors also note that a version of this paper was presented at the McGraw-Hill Ryerson's National Teaching and Learning Conference, St. John’s, NL, May 2011.

Correspondence concerning this article should be addressed to Tim R. Claypool, College of Education, University of Saskatchewan, \#28 Campus Drive, Saskatoon, SK, S7N 0X1, (306) 966-6931 (office), tim.claypool@usask.ca

\begin{abstract}
Although there is momentum among Canadian educators to incorporate Aboriginal content and epistemology into pre-kindergarten to postsecondary education, the learning and assessment of Aboriginal students remains subjugated by a Western perspective. The purpose of this article is to explore ideal learning contexts for Aboriginal students and juxtapose these ideas with the predominant learning and assessment tactics used in a school. Data for this qualitative study were collected via five focus groups involving grandparents/caregivers, representatives from Aboriginal organizations, and educators of one Saskatchewan school. Analyzed through Aboriginal and Western epistemologies, results indicated that, for Aboriginal students, learning and assessment are holistic experiences, and educators need to balance students' academic assessment with other physical, emotional, and spiritual forms of assessment. These findings suggest that educators need to depart from the zone of cognitive competence and move toward promoting an educational zone of trustful intuition.
\end{abstract}

Keywords: Aboriginal content and epistemology; holistic; learning and assessment 


\section{Redefining Learning and Assessment Practices Impacting Aboriginal Students: Considering Aboriginal Priorities via Aboriginal and Western Worldviews}

Across Canada there is momentum to improve the experiences of Aboriginal students in prekindergarten to postsecondary education. As the Saskatchewan Ministry of Education (2010) stated, "The Ministry . . . is committed to improving the education of Aboriginal Peoples" (p. 52). The Council of Ministers of Education, Canada (2010) underscored Aboriginal education as one of its core priorities, as outlined it in its Canada's Ministers of Education Advance Learn Canada 2020 Priorities document. Prime Minister Steven Harper has publically committed to working with Shawn Atleo (National Chief of the Assembly of First Nations) to improve educational opportunities for Aboriginal peoples (Galloway, 2010). To nurture Aboriginal student success within Canadian public schools, governmental officials and educational leaders are also implementing the necessary changes to school culture and classroom experiences, namely by insuring Aboriginal content (including Treaty education), resources, and ways of knowing are infused into curricula (see Benjoe, 2008; Hanson, 2008; Martin, 2010). Even with these processes in motion, educational stakeholders seemed to have overlooked a key feature related to educational success for Aboriginal students. In addition to refining curricula to incorporate Aboriginal voice and identity, student learning and assessment techniques need to parallel Aboriginal worldviews and ways of knowing.

This perceived failure to utilize Aboriginal learning and assessment that is particularly grounded in an Aboriginal worldview may be because there is limited literature on the topic. Indeed, there is a raft of literature describing different assessment techniques for students in general (e.g., Falchikov, 2005; Gredler \& Johnson, 2004; Kallick \& Colosimo, 2009; Oosterhof, 2009; Palloff, 2009; Shea, Murray, \& Harlin, 2005; Stevens \& Levi, 2005; Tanner, 2001). Yet, when refining the focus to specifically target Aboriginal student assessment imbued with an Aboriginal perspective, we found few documents (e.g., Carjuzaa \& Ruff, 2010; Sawa, 2009).

Within this qualitative study, we address this research void. The purpose of this article is to explore ideal learning contexts for Aboriginal students and to juxtapose these ideas with the predominant learning and assessment tactics used in a Saskatchewan school.

\section{Aboriginal and Western Worldviews}

A worldview is a collection of perceptions, beliefs, and values held by an individual or group of individuals pertaining to the structure of the universe and its philosophical and physical association to life. In what follows, we present a description of Aboriginal and Western worldviews.

\section{Aboriginal Worldview}

Integral to Aboriginal worldviews, is a physical, intangible, and highly intricate relationship between all things on earth, such that "everything is one” (Atleo, 2004, p. xi). Based on this premise, each student needs to find his or her distinctive purpose in life by connecting with self, family, community, and the natural world. For Aboriginal students, learning and assessment finds its genesis in the self and then extends toward family, community, and the 
universe; once learning and assessment is extended toward the influence of others and society, it then embodies a cyclical action by returning to the self in the form of self-reflection and personal growth. In such a manner, Aboriginal learning and assessment are a reciprocal circular concept of self-family-community.

Employing the concepts permeated within Aboriginal worldviews means embracing the power and potential of subjective personal knowledge. Aboriginal epistemology is grounded in understanding oneself by unleashing the capacities of intuition, the inner spirit, and the unknown. This unique exploration of self is a personal journey of constant development. Miller, Cassie, and Drake (1990) believed self-introspection has the power to promote skill development and strengthen spiritual attunement with and for the environment. In such ways, learning is an introspective realization of how the self is an elaborate, balanced network of mind, body, emotion, and spirit, all of which are connected to the natural environmental forces of life.

Another aspect of an Aboriginal worldview incorporates knowledge pertaining to the Medicine Wheel (Elliott, Halonen, Akiwenzie-Damm, Methot, \& George, 2004; Walker, 2001; Whiskeyjack, 2000; Wilson, 1994). There are many Aboriginal teachings of the Medicine Wheel and many cultural variations of its themes. For those Aboriginal people who use the Medicine Wheel, its teachings describe four components of a balanced lifestyle (or states of being): the intellectual, physical, emotional, and spiritual (Preston, 2011). In examining the states of being, the Medicine Wheel addresses a person's location in relation to individual, family, community, and nation contexts.

\section{Westernized Worldview}

As compared to an Aboriginal worldview, a Western worldview represents life within demarked, finite boundaries, where time is a linear concept and space is a three-dimensional physical entity. Years are broken down into months; months are subdivided into weeks; weeks are broken into days, which are then further compartmentalized into hours, minutes, seconds, and portions of seconds. Within these confinements, teaching and learning are delivered within preauthorized time units (Macbeth \& Dempster, 2009). This linear value system is reflected through how people interact (Indian and Northern Affairs Canada, 1999). For example, within humanfocused environments such as schools, the cultural norm is that subject-specific classes are scheduled, objectives are created, and teacher and student deadlines ensure completion of tasks.

Westernized standards for student assessment are often presented through processes that are subject-specific, time-bound, competitive, and based on written documentation depicting quantifiable results (Preston, 2011). Popular terms related to such student assessment include evidence-based, curriculum-based, daily data collection, goal-oriented, work samples, benchmarks, anecdotal notes, checklists, portfolios, rubrics, grades, and criterion-referenced measures (Gredler \& Johnson, 2004; Oosterhof, 2009; Shea et al., 2005). These methods primarily promote cognitive growth reflected through rational, linear, and accountable actions. Western forms of student assessment are predominantly based on achieving written goals or curricular outcomes, and the grades attained from participation in school-related activities and assessment methods primarily focus on one dimension of learning - the cognitive. For the most 
part, Western assessment techniques neglect to address the physical, emotional, and spiritual domains of students.

\section{Research Design, Participant Description, and Data Analysis}

The data source for this research was five focus group interviews (Fontana \& Frey, 2005: Puchta \& Potter, 2004). Focus group interviews, employed over 2 months, involved grandparents or caregivers (one focus group), representatives from Aboriginal organizations (one focus group), and educators of one Saskatchewan school (three focus groups), totalling 20 participants. Although invitations were extended to several parents or grandparents or caregivers, only two grandparents responded. The second focus group was attended by a variety of people who represented Aboriginal organizations in partnership with the school and/or school division. Six participants, most of whom were Aboriginal, attended this focus group. The last three focus groups, involving 12 participants in total, was attended by the principal, the vice-principal, teachers, and learning assistant teachers.

To facilitate trust and comfort between researchers and participants, official transcripts were not recorded. In order to honour the process of capturing the voice of participants without literally taking away their voice in the form of an audio recording, the researchers used a somewhat unique method of data collection. Focus group questions were asked to participants, and, during the ensuing discussions, the researcher orally paraphrased participant comments. After the participant agreed on a paraphrased comment, the researcher wrote the remarks on large chart paper posted on the wall. This process used a form of member check and data credibility (Lincoln \& Guba, 1985) that enabled participants to build on the written responses of others. In analyzing the qualitative data, we acknowledged conceptual similarities in respondents' comments, grouped responses into similar categories, and sought the emergence of larger patterns or themes (Creswell, 2007; Kruegar, 1998).

\section{Research Results}

We provide the thematic results of each focus group (grandparent or caregiver, Aboriginal representatives from provincial organizations, and selected educators) and follow these findings with an analytical thread pertaining to Aboriginal and Western worldviews. Through italicized quotes, we highlight some of the information documented on the chart paper used during the focus groups.

\section{Grandparents: Know Oneself}

Grandparents expressed their belief that, before a student can truly be engaged in learning, a student must know him or herself, possess positive self-esteem, and have a constructive attitude toward learning. Grandparent A explained how the intellectual, emotional, and spiritual guidance provided by her family had been instrumental to her positive attitude toward learning. She indicated that her own grandmother "brought her up" and taught her the traditional "ways of being," thereby instilling an openness to learn. Grandparent A explained how important it is for a child to possess a spiritual knowledge in tune with cultural beliefs and traditions. These points are vital features of "knowing oneself." 
Grandparent B wanted her grandson to "experience the beauty of the First Nations culture.” She expressed pleasure in hearing her 7-year-old grandson talk about his responsibility to Mother Earth. Grandparent B perceived that her grandson's environmental stewardship was influenced by the instruction he received from his Cree teacher in school. Grandparents talked about the importance of learning Aboriginal traditions through stories, songs, legends, and the Indigenous language that is often used to convey this information. She believed knowledge of traditions and customs contributed to the students' ability to "love yourself and be good to yourself."

Both grandparents explained that an Aboriginal student must first "love self, care for self, and see that everything around you is well and good." They believed that when these personal features are in place, learning evolves naturally for a child. Both grandparents agreed that before a child can engage in any learning process, he or she must "line up heart, mind, and God." These grandparents explained that nourishing a positive, admirable character begins through family. Grandparents articulated their belief that parents or caregivers must "plant [positive] seeds in formative years"; they identified these metaphorical seeds to be self-confidence, self-respect, and self-esteem. Such comments underscored the point that a positive self-image is a prerequisite to eventful learning. They indicated that a child also needs guidance from traditional teachings to help them know "how to be." Grandparents explained that once the inner strength of a child is established, an individual is empowered to face life's challenges.

The grandparents recognized the school culture as an influential component of the student's positive self-development. Both grandparents were complimentary of the school, which their grandchildren attended, describing the school's atmosphere as "tremendous" and "rich." They perceived that the low number of students enrolled in each classroom was a contributing factor to their grandchildren's healthy spirits. The grandparents unanimously endorsed the policy of three-way report card conferences that were organized through the school. These meetings involved the teacher, student, and parent or caregiver contributing to a discussion pertaining to the student's progress, capability, assessment, and overall evaluation. Grandparents viewed this event as a verbal contract between teacher, student, and parent or caregiver.

Analytical thread. In analyzing the perceptions of grandparents, features of an Aboriginal worldview become transparent. These grandparents explained that student learning must begin by focusing on the individual, the center of the Medicine Wheel. In many Aboriginal cultures, the individual is located at the center of the Medicine Wheel. As Elder Mary Lee (2006) stated:

The fire is in the center of the Medicine Wheel. This is where the meaning of the teachings comes from. For me this fire is also the self. When you look at the Medicine Wheel, you start from the self. (p. 3)

Kind, Irwin, Grauer, and de Cosson (2005) and Wilson (1994) depicted the Medicine Wheel as an individualized learning model through which personal empowerment and healing are achieved. Emphasizing the individual at the center, the Medicine Wheel expounds the journey of the human spirit and conveys how this journey is embodied in the physical realm (Elliott et al., 2004). 
Applying an Aboriginal perspective, each individual comes to earth with a purpose (Kainai Board of Education, 2004), and, through differentiated learning experiences and selfreflection, each individual naturally uncovers his or her unique purpose. Grandparents explained that learning and assessment is a personal experience; the essence of learning and selfassessment must begin with a focus on the heart and soul of the student and extend to envelop relationships with family, community, and nations. Similar teachings are reflected through the Aboriginal view that life is an interconnected web of experiences.

Another component of the Aboriginal worldview is its focus on family relationships and group wellness, a point that surfaced within the comments of grandparents. Social networking among family and community members results in intimate bonding, ensuring the protection, survival, and prosperity of all those within the community circle. Within Aboriginal cultures, relationships are pervasive, profound, and reciprocal in nature (Brayboy \& Maughan, 2009). From an Aboriginal perspective, a person cannot survive on his or her own (Kainai Board of Education, 2004). This statement verifies the life-saving importance placed on family and community and that fecund learning exists within a socially-rich environment.

\section{Representatives From Aboriginal Organizations: Disparity Between Aboriginal Contexts and Westernized Styles of Learning and Assessment}

On to the topic of assessment, participants of this focus group stated that Aboriginal students had been "tested to death." In addition to incessant testing, participants indicated their belief that many of the assessment techniques used with Aboriginal students were a liability to student success. For example, culturally-foreign items on tests, Aboriginal students being tested in their second language, and the challenging lifestyles experienced by many Aboriginal students negatively impacted their test results. Participants explained that social problems, such as poverty and hunger, were stark realities that many Aboriginal students faced on a daily basis. Participants continued by saying that most Aboriginal students experienced segregation, alienation, discrimination, and racism on a daily basis. Faced with such social injustices, participants questioned how mainstream assessment techniques performed on Aboriginal students could produce any level of accuracy.

As similarly expressed by the grandparents, participants of the second focus group emphasized that before quality assessment can occur Aboriginal students need to feel a "sense of belonging." They indicated that Aboriginal students need to, "be proud of who [they] are." Inherent in this belief is a sense that promoting an Aboriginal student's sense of belonging is embellished by teachers who participate in ongoing professional development that is particularly attuned to the needs of Aboriginal students. In such a way, participants explained that teachers can "capitalize on their [the students'] gifts."

A discussion ensued around the school division's success with implementing professional development through the philosophy of Dr. Brokenleg's, Circle of Courage ${ }^{\mathrm{TM}}$ (Brendto \& Brokenleg, 2001). The Circle of Courage ${ }^{\mathrm{TM}}$ model is based on four Aboriginal lifestyle principles: belonging, mastery, independence, and generosity. The model provides a culturallysensitive way of infusing Aboriginal philosophies into curricula, instruction, and assessment. 
Teachers were encouraged to participate and reflect on this model, which begins with the need for each student to possess a sense of belonging in family, school, and community.

Participants expressed their belief that a student's sense of belonging is positively influenced when trusting relationships exist between the teacher and parent or caregiver. Because many parents or caregivers doubt their ability to contribute to academic discussions with a teacher or administrator, they need reassurance that their voice is important. Additionally, participants highlighted that the parents' or caregivers' past school experiences may have had a negative impact on their perceptions of current school practices and on their willingness to participate in school-related activities. Some Aboriginal parents are "afraid of being judged" for fear of being perceived as inferior to societal norms. There was a belief that contributing to a student's sense of belonging involves teachers and administrators contributing to a parent's or caregiver's sense of belonging in the school.

Analytical thread. The Circle of Courage ${ }^{\mathrm{TM}}$ is a philosophy describing the four cultural birthrights of all children, regardless of race. Of these four birthrights (belonging, mastery, independence, and generosity), belonging, or the ability to have a great closeness and trust of others, is the most crucial (Brendto \& Brokenleg, 2001). "The universal longing for human bonds is cultivated by relationships of trust so that a child can say, 'I am loved'” (Brendtro, Brokenleg, \& Van Bockern, 2002, p. 137). A student's sense of belonging is met by creating and nurturing positive relationships with family, friends, and the school-by focusing on nurturing family and community or collective wellbeing. Similar beliefs were threaded throughout the grandparents' and Aboriginal representatives' comments. The Circle of Courage ${ }^{\mathrm{TM}}$ reflects many of the teachings present in the Medicine Wheel, as both concepts utilize the symbol of the circle to portray life as an interconnected web of existence.

Brendtro, Brokenleg, and Van Bockern (2002) highlighted that for Aboriginal peoples knowledge of self is connected to cultural identity. Without traditional and cultural knowledge of self (which is intricately connected to self-confidence), a person is susceptible to social, psychological, and learning problems. It is for this reason that Fred (2000) explained, "Native people are being encouraged to get in touch with their culture and to use it for the betterment of their people” (p. 301). As one example of many, traditional Aboriginal dance has been identified by the Beardy Okemasis First Nations (Saskatchewan) as playing a vital role in keeping young people in touch with First Nations community values (Hughes, 2007). A related but more academic challenge would be to provide Aboriginal students with relevant learning and selfassessment opportunities rooted within Aboriginal traditions.

\section{Educators: Myriad Forms of Westernized Styles of Learning and Assessment}

The focus groups with educators addressed the topic of student assessment. When asking educators to describe the type of data they collected for student assessment purposes, their list was long. First, they listed standardized tests, which included the Canadian Test of Basic Skills (CTBS), Canadian Achievement Test (CAT) III/IV, Wechsler Intelligence Scale for Children (WISC)-IV, Behavior Assessment System for Children (BASC), Woodcock Reading Mastery Test (WRMT), Saskatchewan Assessment for Learning (AFL) tests, as well other formal tests. Then educators described a number of criterion and curriculum-referenced forms of assessment, 
which included mainstream tests, computer programs, Analyze Design Access Participate Train (ADAPT) checklists, and a specific math series test. Educators spoke of health-related assessment tests and explained that, whenever possible, they use the information provided from medical assessment and referral forms supplied by physicians and health specialists. As well, speech and language pathologists assessed some of the students' language abilities, and occupational therapists conducted physical assessments on some students.

Educators went on to describe the different student assessment techniques that teachers commonly employed. Some teachers observed students in class and filled in behavioral checklists. Teachers sometimes asked students to self-reflect, set personal goals, and reflect on personal development by completing self-evaluation sheets. Many teachers maintained anecdotal notes describing student success and behavior. To assess the students' ability to decode words and meaning, teachers listened to student reading. Many teachers used rubrics as a form of student assessment. Some teachers invited students to participate in group work, co-assessed by teachers and students. In addition, teachers assessed student homework, portfolios, demonstrations, written tests, and oral presentations. Teachers were involved with personal interviews with students, parents or caregivers, and outside agencies. Teachers also created evaluative report cards, which were distributed three times during the school year, and engaged in three-way (teachers, student, and parent or caregiver) conferences to discuss student results.

After a rich discussion about the types of student assessment techniques used by educators, educators were asked to identify any gaps in the data collection process pertaining to Aboriginal students. Educators expressed their view that a more holistic approach was needed for Aboriginal students. They explained that the assessment strategies they employed primarily focused on assessing the cognitive domain of students. Assessment of the physical, emotional, spiritual and culture domains of students were not given equal attention. Educators indicated their desire for participating in professional development to help them holistically assess the abilities of Aboriginal students.

Analytical thread. In analyzing these data, concepts of the Western worldview pertaining to assessment are obvious. Indeed, teachers are engaging in a number of studentcentered, reflective assessment processes; however, the ultimate product is that teachers teach curricular content, in set grades, and at set times of the day. They are mandated to create individualized report cards during set times of the year, and their assessment largely addresses the cognitive development of students. For Aboriginal students, learning is predominantly assessed through quantitative means. In contrast, ideally for Aboriginal peoples, learning is a lifelong journey, which, when assessed, is done through personalized qualitative means. These data show that disparity exists between Western-based assessment techniques and the Aboriginal perspective of assessment. When teachers, students, and parents operate from different worldviews, student learning, student assessment, and the communication of this information is not ideal.

\section{Recommendations}

The kind of knowledge and styles of assessment found in Canada's education system are those that can be manipulated within a rational, linear, controlled, and subject-demarked classroom 
environment. Classroom culture is often entrenched in pragmatic, compartmentalized, and competitive educational doctrines, which situate cognitive competence above physical, emotional, spiritual, and social abilities of students. The emphasis educators place on this zone of cognitive competence amplifies and justifies student assessment to be factual, measureable, highly detailed, and goal-related. However, all educational stakeholders must be reminded: "Not everything that can be counted counts, and not everything that counts can be counted" (Cameron, 1963, p. 13). ${ }^{1}$

Educational systems need to depart, at least partially, from this zone of cognitive competence and move toward promoting an educational zone of trustful intuition. Within this zone of trustful intuition, educators would promote a style of learning which targets student development of emotional and spiritual domains, encouraging students to acknowledge their emotional reactions and their immediate instincts when approaching learning situations and important decisions. For example, when self-reflecting, students need to be encouraged not to question their cognitive beliefs but to rely upon their body, heart, and soul intuitions. In sum, to support this zone of trustful intuition, educators need to address the physical, emotional, spiritual, and social wellbeing of their students. In support of this point, Johnston and Claypool (2010) proposed a multi-method assessment model that illustrates how data sources, assessment methods, and areas assessed can be combined so that both Aboriginal and non-Aboriginal ways of knowing are respected and reported. In sum, a zone of trustful intuition is created when teachers facilitate a classroom environment infused with respect, relationships, and reciprocity, all of which stimulate positive learning and assessment experiences for students.

Aboriginal pedagogy and epistemology need to permeate the atmosphere of classrooms, while simultaneously welcoming all learners, regardless of cultural background. To do so, first, educators need to embrace the idea that education is the journey of life; it is, therefore, a unique experience for each student. Student self-assessment (embodied through cognitive, physical, emotional, spiritual, and social domains) needs to be intricately woven into all learning experiences. When these self-assessments are combined with other forms of assessment data, such as standardized or criterion-referenced test scores, a more holistic picture of the individual emerges. Students absorb learning (a natural and social event) as they observe and/or participate in cooperative events, storytelling, demonstrations, role modeling, group discussion, selfreflection, talking circles, apprenticeships, and other in vivo experiences. In other words, the processes of learning become as important as the product. If this culturally sensitive philosophy of learning is adopted, assessment practices must adapt to ensure that concrete changes are reflected in actual policies and assessment frameworks.

Learning opportunities need to encompass the concepts of reciprocity, self-discovery, empathy, and respect for each learner. Educational activities, centering on pertinent life tasks, welcome children, adolescence, adults, and Elders working collaboratively to achieve communal goals. Ultimately, schools are to reflect a learning culture targeting student achievement that empowers the students, their families, and their local communities to attain cognitive, emotional, physical and spiritual wellbeing. As a result, an individual's learning spirit (Battiste, 2010) would be nourished throughout their lifetime with the seeds of this ideal being planted within our public school systems. 


\section{References}

Atleo, E. R. (2004). Tsawalk: A Nuu-chah-nulth worldview. Vancouver, BC: UBC Press.

Battiste, M. (2010). Nourishing the learning spirit: Living our way to new thinking. Education Canada, 50(1), 14-18.

Benjoe, K. (2008, September 21). Treaty education mandatory for all school children. Regina Sun, pp. A1.

Brayboy, B. M. J., \& Maughan, E. (2009). Indigenous knowledge and the story of Bean. Harvard Educational Review, 79(1), 1-21.

Brendtro, L., \& Brokenleg, M. (2001). The Circle of Courage: Children as sacred beings. In L. Lantireri (Ed.), Schools with spirit (pp. 39-52). Boston, MA: BeaconPress.

Brendtro, L., Brokenleg, M., \& Van Bockern, S. (2002). Reclaiming youth at risk: Our hope for the future (Rev. ed.). Bloomington, IN: National Educational Service.

Cameron, W. B. (1963). Informal sociology: A casual introduction to social thinking. New York, NY: Random House.

Carjuzaa, J., \& Ruff, W. G. (2010). When Western epistemology and an Indigenous worldview meet: Culturally responsive assessment in practice. Journal of Scholarship of Teaching and Learning, 10(1), 68-79.

The Council of Ministers of Education, Canada. (2010, September 24). Canada's Ministers of Education advance Learn Canada 2020 priorities. Retrieved from http://www.cmec.ca/Press/2010/Pages/2010-09-24-2020.aspx

Creswell, J. W. (2007). Qualitative inquiry \& research design: Choosing among five approaches (2nd ed.). Thousand Oaks, CA: Sage.

Elliott, M., Halonen, D., Akiwenzie-Damm, K., Methot, S., \& George, P. (2004). Empowering the Spirit II: Native literacy curriculum (2nd ed.). Owen Sound, ON: Ningwakwe Learning Press.

Falchikov, N. (2005). Improving assessment through student involvement: Practical solutions for aiding learning in higher and further education. London, UK: RoutledgeFalmer.

Fontana, A., \& Frey, J. H. (2005). The interview: From neutral stance to political involvement. In N. K. Denzin \& Y. S. Lincoln (Eds.), The Sage handbook of qualitative research (3rd ed., pp. 695-727). Thousand Oaks, CA: Sage. 
Fred, R. (2000). Foreword to “resistance and renewal.” In R. M. Mann (Ed.), Juvenile crime and delinquency: A turn of the century reader (pp. 293-302). Toronto, ON: Canadian Scholastic Press.

Galloway, G. (2010, December 17). PM to make native education a priority. The Globe and Mail, pp. A4.

Gredler, M. E., \& Johnson, R. L. (2004). Assessment in the literary classroom. Boston, MA: Pearson.

Hanson, D. (2008, February 28). K-12 program tailored for first nations students. The Vancouver Sun, pp. B1

Hughes, L. (2007, Spring). The dance will lead. Prairies North: Saskatchewan's Magazine for Good Prairie Living, pp. 54-63.

Indian and Northern Affairs Canada. (1999). Aboriginal awareness workshop: Guide to understanding Aboriginal cultures in Canada. Ottawa, ON: Author.

Johnston, A., \& Claypool, T. (2010). Incorporating a multi-method assessment model in schools that serve First Nations, Inuit, and Métis learners. Native Studies Review, 19(2), 121-138.

Kallick, B., \& Colosimo, J. (2009). Using curriculum mapping and assessment data to improve learning. Thousand Oaks, CA: Corwin Press.

Kainai Board of Education, Métis Nation of Alberta, Northland School Division, \& Tribal Chiefs Institute of Treaty Six. (2004). Aboriginal Studies 10: Aboriginal perspectives. Edmonton, AB: Duval House.

Kind, S., Irwin, R. L., Grauwer, K., \& de Cosson, A. (2005). Medicine Wheel imag(in)ings: Exploring holistic curriculum perspectives. Art Education, 58(8), 33-38.

Krueger, R. A. (1998). Analyzing and reporting focus group results. Thousand Oaks, CA: Sage.

Lee, M. (2006). Cree (Nehiyawak) teaching. Retrieved http://www.fourdirectionsteachings.com/transcripts/cree.pdf

Lincoln, Y. S., \& Guba, E. G. (1985). Naturalistic inquiry. Thousand Oaks, CA: Sage.

Macbeth, J., \& Dempster, N. (2009). Introduction: Leadership and learning: Making the connections. In J. Macbeth \& N. Dempster (Eds.). Connecting leadership and learning: Principles for practice (pp. 1-3). New York, NY: Routledge.

Martin, N. (2010, October 30). Manitoba schools to teach students about treaties. Winnipeg Free Press, pp. B3. 
Miller, J. P., Cassie, J. R., Drake, S. M. (1990). Holistic learning. Toronto, ON: OISE Press.

Oosterhof, A. (2009). Developing and using classroom assessment (4th ed.). Upper Saddle River, NJ: Pearson.

Palloff, R. M. (2009). Assessing the online learner: Strategies for faculty. San Francisco, CA: Jossey-Bass.

Preston, J. P. (2011, March). Practices of Aboriginal youth leadership: A multi-worldview on the $21^{\text {st }}$ century leadership. Saskatoon, SK: Saskatoon Public School Division (under the auspices of the Saskatchewan Educational Leadership Unit).

Puchta, C., \& Potter, J. (2004). Focus group practice. London, UK: Sage.

Saskatchewan Ministry of Education. (2010). 2010 Saskatchewan education indicators report: Prekindergarten to Grade 12. Regina, SK: Author. Retrieved from http://www.education.gov.sk.ca/2010-Indicators

Sawa, R. (Ed.). (2009). Assessing students’ ways of knowing. Regina, SK: Canadian Centre for Policy Alternatives.

Shea, M., Murray, R., \& Harlin, R. (2005). Drowning in data? How to collect, organize, and document student performance. Portsmouth, NH: Heinemann.

Stevens, D. D., \& Levi, A. (2005). Introduction to rubrics: An assessment tool to save grading time, convey effective feedback, and promote student learning. Sterling, VA: Stylus.

Tanner, D. E. (2001). Assessing academic achievement. Boston, MA: Allyn and Bacon.

Walker, P. (2001). Journey around the Medicine Wheel: A story of Indigenous research in a Western university. The Australian Journal of Indigenous Education, 29(2), 18-21.

Whiskeyjack, F. (2000, June 1). Medicine Wheel. Wind Speaker. Retrieved from http://www.thefreelibrary.com/Medicine+wheel.-a030565110

Wilson, R. I. (1994). Medicine Wheels: Ancient teachings for modern times. New York, NY: Crossroads.

\section{Endnote}

${ }^{1}$ This quote is also often attributed to Albert Einstein, though no formal publication trail of this quote from Einstein is accessible. 